\title{
Seasonal shifts in host usage in Uroleucon gravicorne (Homoptera: Aphididae) and implications for the evolution of host alternation in aphids
}

NANCY A. MORAN Museum of Zoology and Division of Biological Sciences, University of Michigan, Ann Arbor, Michigan

ABSTRACT. 1. Uroleucon gravicorne (Patch) feeds on annual Erigeron species and on perennial Solidago species.

2. To test whether Solidago and Erigeron are analogous to winter and summer hosts of typical host-alternating aphids, reproductive performance, host preferences, and host associations were measured for E.strigosus, S.juncea and S.nemoralis during spring, summer and autumn.

3. Caged individuals can reproduce on both genera throughout the season, though colonies are rare on Solidago during summer.

4. Developmental rate, adult weight, and fecundity decline between May and August on all hosts; however, the drop is least on E.strigosus, intermediate on S.nemoralis, and greatest on S.juncea.

5. Throughout the season, reproductive performance is at least as great on Erigeron as on Solidago, the difference being least in spring.

6. Soluble nitrogen content shows the same seasonal trends as reproductive performance, declining in all hosts, but declining least in E.strigosus.

7. Preference tests and field records show that U.gravicorne moves from Solidago to Erigeron when the first alatae mature in late spring, feeds on Erigeron during the summer, and, in late summer, returns to Solidago where overwintering eggs are laid.

8. Solidago is not nutritionally superior during spring or autumn; its use during those seasons may result from the need for good oviposition sites.

Key words. Aphid, Uroleucon, host-alteration, herbivore, heteroecy, phenology.

\section{Introduction}

Seasonal shifts between host taxa are known for several insect groups (Claridge \& Wilson, 1978; Melber et al., 1981), but the superfamily Aphidoidea contains most examples. In the most familiar host-alternating (or heteroecious) life cycle, overwintering eggs and the first few spring generations occur on

Correspondence: Dr N. A. Moran, Museum of Zoology and Division of Biological Sciences, University of Michigan, Ann Arbor, Michigan 48109, U.S.A. a woody plant, the 'primary' host. A winged generation then migrates to plants which are usually herbaceous and taxonomically unrelated to the winter host. These summer hosts support a succession of alate-initiated colonies which give rise in fall to winged males and winged gynoparae (mothers of sexual females). These fly to winter hosts where wingless sexual females develop, mate, and deposit overwintering eggs.

Although host alternation characterizes only about $10 \%$ of modern aphid species (Eastop, 1972), it has been central in the 
evolution of their life cycles and host relations. A much greater proportion of species are apparently derived from heteroecious ancestors (Hille Ris Lambers, 1950), and the phenomenon has arisen multiple times in an array of aphid taxa. Furthermore, comparison of morphologies and life cycles of alternating and non-alternating taxa indicates that host alternation has been critical in the evolution of morph differentiation and host acquisition (Eastop, 1972, 1977; Hille Ris Lambers, 1966). A striking feature of aphid biology is the widespread occurrence of clonal polymorphism, in which genetically similar individuals may have very different structures and habits; almost all extreme examples of this phenomenon are associated with host alternation.

According to the most widely held theory, host alternation is an adaptation to seasonal fluctuations in phloem nutrient levels (Kennedy \& Stroyan, 1959; Mordvilko, 1928). In perennials, these levels are high in spring when nitrogen is being mobilized for growth; once leaves are fully developed, phloem nutrient levels drop (Dixon, 1971; Mittler, 1953; Parry, 1979). Host alternating species escape this midsummer adversity by moving to herbaceous plants which are actively growing and thus more nutritious during summer. By itself, the complementary host growth theory implies that all phloem feeders should alternate hosts. An adequate theory for the evolution of host alternation should explain not only how the phenomenon originates and is maintained where it occurs, but also why it is more frequent in aphids than in other groups and, ideally, why it characterizes some aphids and is absent in others, including whole subfamilies, such as Drepanosiphinae and Callaphidinae.

Almost all studies of host alternation have been directed at a few highly specialized, obligately heteroecious members of one subfamily, the Aphidinae. Such studies are especially unlikely to increase our understanding of selective factors involved in the origin of heteroecy, particularly predisposing features in aphids. Here, we are more likely to benefit through attention to species which show more flexibility in seasonal shifts in host affinities. In this paper, I detail such a life cycle and consider its implications for theories of host alternation in aphids and of plantherbivore interactions in general.

The large genus Uroleucon Mordvilko is almost completely restricted to the plant family Compositae. Host alternation is unknown, and a typical species uses several plant species within a genus. Uroleucon gravicorne (Patch) is native to eastern North America and has a relatively wide host range, feeding on species of Solidago and Erigeron (Hottes \& Frison, 1931; Leonard, 1936, 1963 , 1964, 1967, 1968; Leonard \& Bissell, 1970; Olive, 1963; Patch, 1919; Richards, 1972; personal observations). The contrasting phenologies of Solidago species (all perennial) and Erigeron species (annual) suggested that U.gravicorne might benefit from seasonal shifts between these genera. In this paper, I report investigations addressing the following questions:

Do relative qualities of hosts, as measured by aphid developmental time, adult size and fecundity, change seasonally?

Do host preferences of colony-initiating winged forms change with season, and, if so, do they shift in directions that would optimize diet?

Do host associations of naturally occurring colonies show corresponding seasonal trends?

Does alate production change with host and season, and how does the observed pattern affect use of host taxa?

Do observed shifts in host quality result from changes in aphid requirements or in some intrinsic property of the plants, soluble nitrogen content for example?

Do factors other than nutritional quality promote seasonality in host usage and are these factors likely to be of general importance in host-alternating aphids?

\section{Methods and Materials}

\section{Host plants}

I selected three of U.gravicorne's hosts, the annual Erigeron stigosus Muhl., and the perennials Solidago juncea Ait and S.nemoralis Ait., for the study, carried out from 1978 to 1981 on the Edwin S. George Reserve (ESGR) in Livingston County, Michigan. These species, together with E.annuus (L.), appear to be the most commonly used hosts in the area. All three frequently grow together in old fields, 
allowing field comparison of aphid performance with minimal differences in microhabitat. Among Solidago species, S.juncea and S.nemoralis contrast sharply in growth form and phenology. S.juncea flowers early (beginning in late July) and produces long rhizomes which may develop into rosettes or into flowering stems. S.nemoralis flowers approximately 4 weeks later and develops only a stout woody caudex from which flowering stems arise each year; consequently, lateral spreading of individual plant clones is minimal.

\section{Seasonal changes in host favourability}

Reproductive performance. Developmental time, adult weight, and fecundity were measured using cages constructed from $35 \times 15 \mathrm{~mm}$ plastic Petri dishes. Edges were lined with foam rubber to form aphid proof seals on plant stems, and each cage half had a $2 \mathrm{~cm}$ diameter ventilation hole covered with fine mesh $(40 / \mathrm{cm})$ Lumite screening. Cages were held in place with plant ties and stakes. Most data were obtained using potted plants in a screenhouse $(4.3 \times 2.5 \times 2.0 \mathrm{~m})$ on the ESGR; thus, differences observed between hosts are probably due to differences in the plants and not in other aspects of the environment. Screenhouse conditions appeared to be within the range in which plants and aphids normally occur; this was supported by comparison of maximum and minimum temperatures recorded in the screenhouse and in two field sites. The phenologies, sizes and appearances of screenhouse plants were well within the ranges exhibited by naturally occurring plants in this area. Potted plants were obtained by transplanting rhizomes with developing shoots (Solidago spp.) and seedlings (E.strigosus) from the field soon after ground thaw in spring; plants were taken from old field and thin oak woodland sites within $5 \mathrm{~km}$ of the ESGR.

In addition to screenhouse data, reproductive performance was measured for a limited number of aphids caged on plants occurring naturally in two old field sites, $2.1 \mathrm{~km}$ apart on the ESGR.

Developmental time from birth to adulthood was measured by caging a reproductive aptera on a plant, checking the cage daily, and removing her as soon as one or more nymphs had been deposited. Usually only 1 day, but occasionally 2 or 3 days, passed before a nymph was produced. As nymphs developed, cage position was adjusted to enable utilization of preferred feeding sites (the uppermost leaves or stem apices according to plant stage). Dates of moulting to adulthood and of first reproduction were recorded $( \pm 24 \mathrm{~h})$. Within $24 \mathrm{~h}$ of first reproduction and within $2 \mathrm{~h}$ of removal from the host, live adults were weighed on a Kahn electromicrobalance. Each cage gave one measure of developmental time and of weight: if the original mother produced more than one nymph within $24 \mathrm{~h}$, I allowed all to develop to adulthood, and used the cage averages.

Developmental times were converted to a measure of day-degrees in order to compare performances of aphids not reared simultaneously. On this scale, each day is transformed to the difference between the average of the maximum and the minimum temperatures and $3.5^{\circ} \mathrm{C}$, the approximate threshold temperature for U.gravicorne's development. This value was obtained by culturing U.gravicorne in a controlled temperature chamber.

Fecundity and proportion of winged progeny were measured by allowing caged apterae to produce nymphs and transferring these mothers to successive cages before nymphs became adult (to avoid confusion between mothers and offspring). Nymphs were allowed to continue feeding until the youngest had reached the third instar (when wing pads permit recognition of alate morphs). They were then removed and numbers of each morph and instar recorded. Each estimate of fecundity required transferring the mother through four to six successive cages. Individual mothers were reared from birth on the host species on which fecundity was evaluated so that host effects on both nymphal and reproductive stages could influence fecundity. They were followed from the fourth instar to ensure that all progeny were counted.

Soluble nitrogen levels. During 1980 each plant species was sampled weekly from 1 May (time of egg hatch that year) to 25 October for determination of soluble nitrogen levels. Samples consisted of whatever part of the plant aphids fed upon: the uppermost leaves in early spring and the uppermost portion of 
the stem during the remainder of the season. Samples were gathered at 10.00-11.00 hours each day, immediately dried (at $50^{\circ} \mathrm{C}$ ), and stored in a freezer.

Prior to analysis, samples were ground in a Wiley mill and extracted in a solution of $2.5 \%$ trichloroacetic acid, $0.02 \%$ phenol and water for $7 \mathrm{~h}$. Total nitrogen content of the extract was determined using a modified Kjeldahl technique (Derman et al., 1978). Two to five samples of each plant species were analysed for each collection date; each was a mixture of many $(>25)$ plant stems.

\section{Seasonal changes in host preferences and usage}

Host preference experiments. To evaluate host preferences, adult alatae were allowed to choose among intact plants in an outdoor screen enclosure $(1 \times 2 \times 0.8 \mathrm{~m})$. Plants were in pots buried up to shoot bases. Three groups of three pots were used, with one pot of each species per group. In each experiment thirtyfive to forty-five alatae were released and left for $48 \mathrm{~h}$; numbers choosing each stem were then recorded. Choice was scored only if an alata had committed herself to a host, as indicated by loss of ability to fly, abdomen enlargement, and, often, nymph deposition.

Patterns of field colonization. In 1981, I located all U.gravicorne colonies in each of three ESGR field sites, ranging in size from 162 to $222 \mathrm{~m}^{2}$. Each contained all three plants, although S.nemoralis was most common in all sites. Totals censused were 246 clones of S.nemoralis, forty-four reproductive stems and 128 leaf rosettes of S.juncea, and fifty-one individuals of E.strigosus. Every plant in each site was checked for aphids every third day during the periods 1 May to $10 \mathrm{July}$ and 20 July to 30 August.

Literature records. To determine whether U.gravicorne shifts host with season over a wider geographic range, I pooled host data from the literature (Leonard, 1936, 1963, 1964, 1967, 1968; Leonard \& Bissell, 1970; Olive, 1963; Patch, 1919), from the collection of the Illinois State Natural History Survey, and from the Canadian National Collection. Records were arranged by date and by host genus (Solidago v. Erigeron).

\section{Results}

\section{Seasonal changes in host fa vourability}

Reproductive performance. Relative favourabilities of hosts change markedly over the season (Figs. 1-4). All three plant species become less favourable during the interval between 1 May and 15 August; developmental times increase and fecundities and adult weights decrease during this period. However, quality declines much more in the Solidago species than in E.strigosus. In spring, developmental times are longest on S.nemoralis, intermediate on S.juncea, and shortest on E.strigosus; adult weights and fecundities rank in the order S.juncea $>$ E.strigosus $>$ S.nemo-

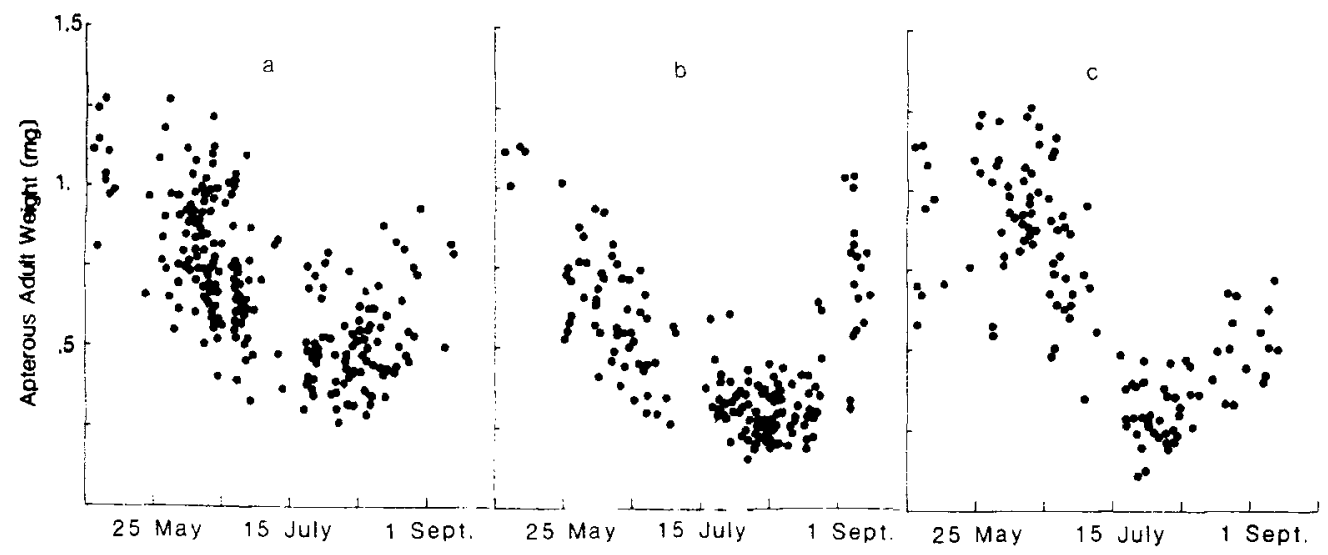

FIG. 1. Apterous adult weight versus time of season for Uroleucon gravicorne. Measures are for apterae reared on (a) Erigeron strigosus, (b) Solidago nemoralis, and (c) Solidago juncea. Aphids were reared on plants in a screenhouse and in the field. 


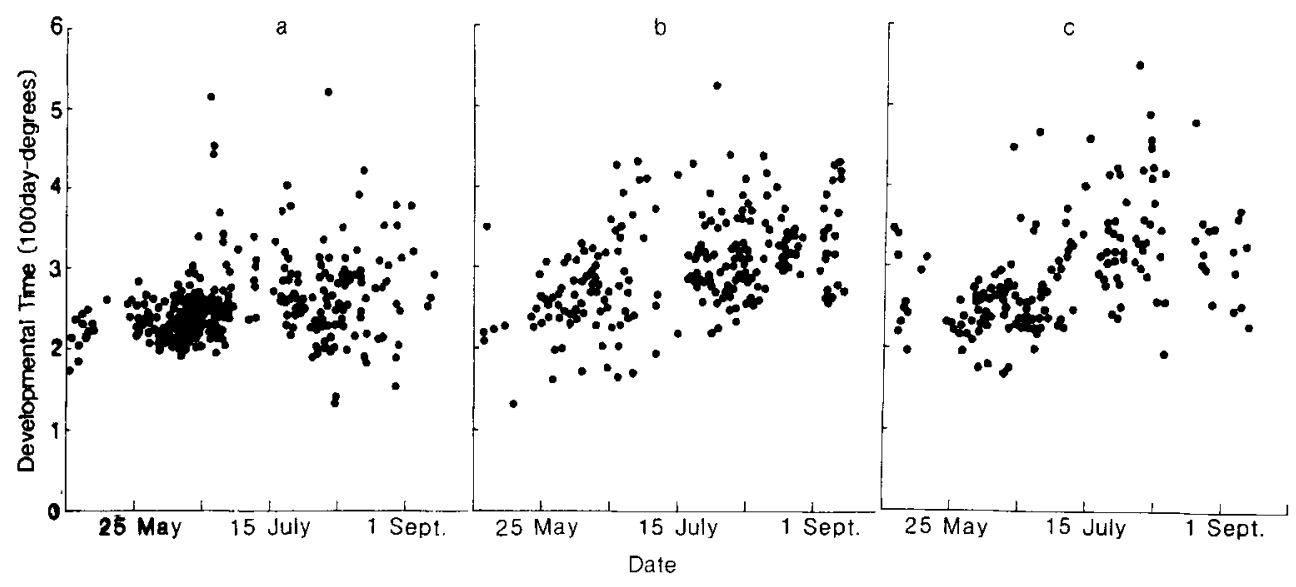

FIG. 2. Developmental time versus time of season for Uroleucon gravicorne. Measures are day-degrees from birth to adulthood for apterae reared on (a) Erigeron strigosus, (b) Solidago nemoralis, and (c) Solidago juncea. Aphids were reared on plants in a screenhouse and in the field.

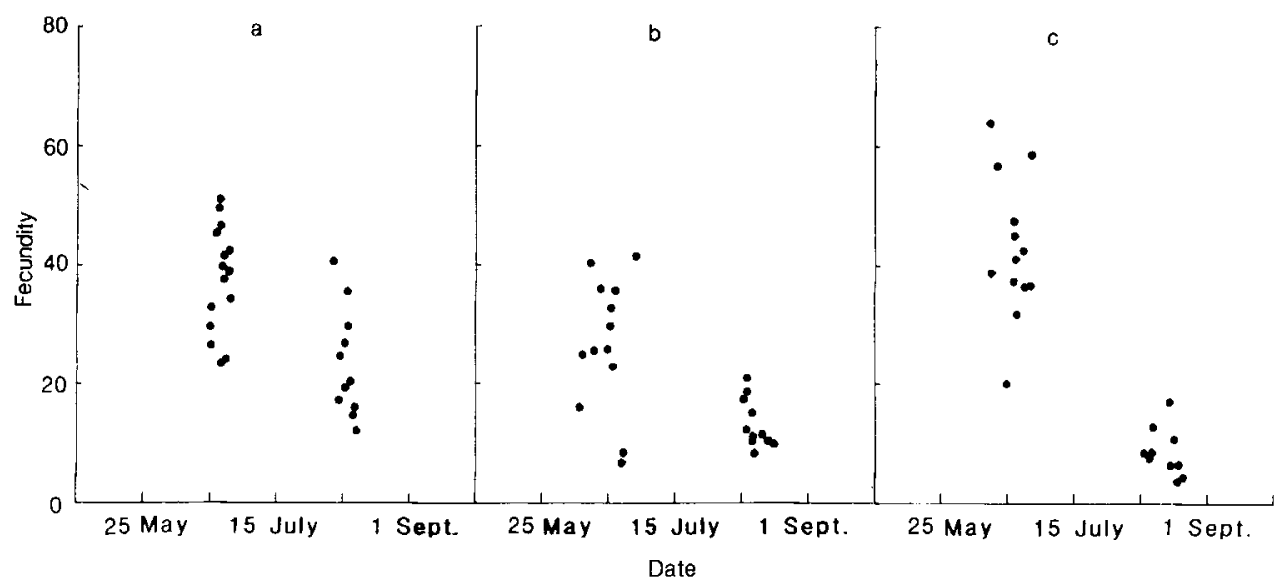

FIG. 3. Fecundity versus time of season for Uroleucon gravicorne. Values are numbers of nymphs produced during the first 400 day-degrees of adulthood for apterae caged in a screenhouse on (a) Erigeron strigosus, (b) Solidago nemoralis, and (c) Solidago juncea.

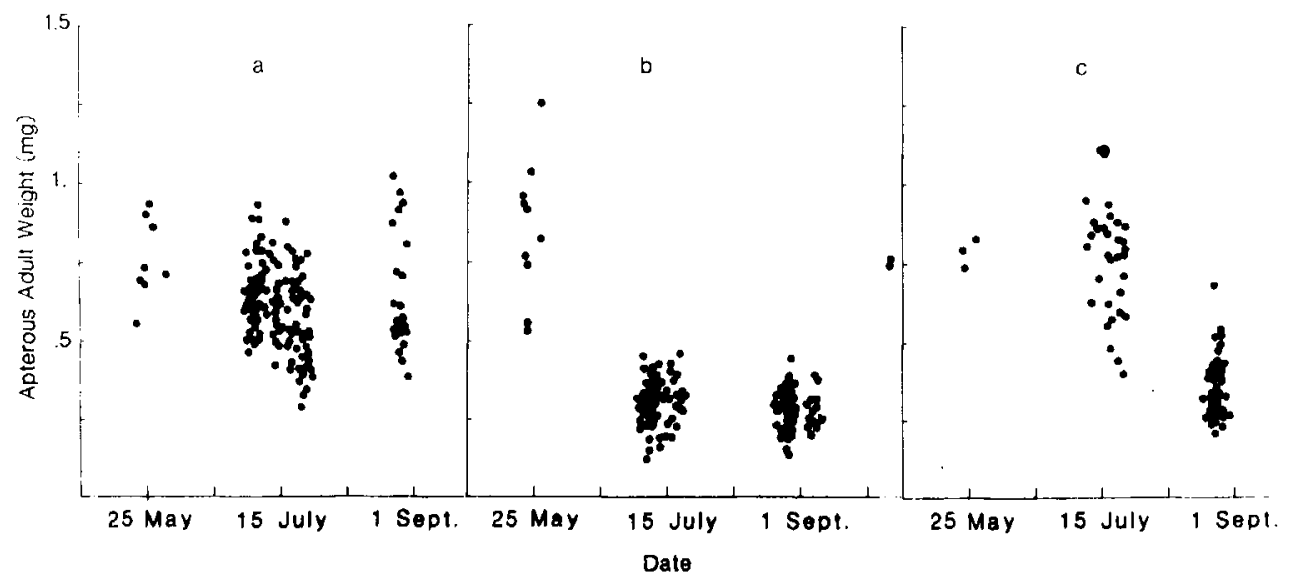

FIG. 4. Weights of field-collected Uroleucon gravicorne apterae collected from naturally occurring colonies on (a) Erigeron strigosus, (b) Solidago nemoralis, and (c) Solidago juncea. 
TABLE: 1. Reproductive performance of Uroleucon gravicorne by host and season.

\begin{tabular}{|c|c|c|c|c|c|c|c|}
\hline \multirow[b]{2}{*}{ Season } & \multirow[b]{2}{*}{ Host plant } & \multicolumn{2}{|c|}{$\begin{array}{l}\text { Day-degrees } \\
\text { to develop }\end{array}$} & \multicolumn{2}{|c|}{$\begin{array}{l}\text { Weight of adult } \\
\text { apterae (mg) }\end{array}$} & \multicolumn{2}{|c|}{$\begin{array}{l}\text { No. of nymphs in } \\
400 \text { day-degrees }\end{array}$} \\
\hline & & Mean & $N$ & Mean & $N$ & Mean & $N$ \\
\hline Spring & $\begin{array}{l}\text { E.strigosus } \\
\text { S.nemoralis } \\
\text { S.juncea } \\
\text { Anova, } P<\end{array}$ & $\begin{array}{c}239.0 \\
260.0 \\
252.7 \\
0.001\end{array}$ & $\begin{array}{r}105 \\
61 \\
62\end{array}$ & $\begin{array}{l}0.86 \\
0.70 \\
0.94 \\
0.001\end{array}$ & $\begin{array}{l}92 \\
43 \\
47\end{array}$ & $\begin{array}{c}37.7 \\
33.4 \\
43.1 \\
0.002\end{array}$ & $\begin{array}{l}15 \\
13 \\
13\end{array}$ \\
\hline Summer & $\begin{array}{l}\text { E.strigosus } \\
\text { S.nemoralis } \\
\text { S.juncea } \\
\text { Anova. } P<\end{array}$ & $\begin{array}{c}267.3 \\
320.8 \\
317.1 \\
0.0001\end{array}$ & $\begin{array}{r}154 \\
130 \\
92\end{array}$ & $\begin{array}{l}0.56 \\
0.34 \\
0.50 \\
0.0001\end{array}$ & $\begin{array}{r}115 \\
104 \\
65\end{array}$ & $\begin{array}{l}36.1 \\
13.4 \\
8.6 \\
0.001\end{array}$ & $\begin{array}{r}8 \\
11 \\
10\end{array}$ \\
\hline Autumn & $\begin{array}{l}\text { E.strigosus } \\
\text { S.nemoralis } \\
\text { S.juncea } \\
\text { Anova, } P<\end{array}$ & $\begin{array}{l}276.1 \\
337.5 \\
310.6 \\
0.005\end{array}$ & $\begin{array}{l}14 \\
28 \\
15\end{array}$ & $\begin{array}{l}0.69 \\
0.65 \\
0.52 \\
0.1\end{array}$ & $\begin{array}{r}8 \\
22 \\
14\end{array}$ & $\begin{array}{l}- \\
- \\
-\end{array}$ & $\begin{array}{l}- \\
- \\
-\end{array}$ \\
\hline
\end{tabular}

TABLE 2. Slopes of regressions of developmental time, apterous adult weight, and fecundity on date, for the period 1 May to 15 August.

\begin{tabular}{llllr}
\hline & Host plant & Slope & 95\% C.I.limits & $N$ \\
\hline Developmental time & E.strigosus & 0.56 & $-1.40,0.88$ & 132 \\
& S.nemoralis & 0.88 & $0.45,1.31$ & 103 \\
Weight of apterous adult & S.juncea & 1.32 & $0.85,1.79$ & 109 \\
& E.strigosus & -0.0074 & $-0.0092,-0.0064$ & 110 \\
& S.nemoralis & -0.0079 & $-0.0087,-0.0060$ & 71 \\
Fecundity & S.junced & -0.0080 & $-0.0095,-0.0055$ & 77 \\
& E.strigosus & -0.30 & $-0.45,-0.15$ & 26 \\
& S.nemoralis & -0.25 & $-0.38,-0.11$ & 24 \\
& S.juncea & -0.60 & $-0.73,-0.46$ & 23 \\
\hline
\end{tabular}

ralis (Table 1). In summer (20 June to 24 August), E.strigosus is far superior to either Solidago species in all three measures of performance (Table 1). Between 1 May and 15 August, the decline in reproductive performance is approximately linear and is least on E.strigosus, as indicated by all three measures (Table 2).

Although more variable, field measures of developmental times and adult weights show the same trends as data from screenhouse plants (Figs. 1 and 2). The higher variability, particularly pronounced in measures of developmental times, probably results from greater variability in microhabitat acting either directly on the aphids or indirectly through the physiological state of the plants. As a further check on the validity of inferring trends from cage experiments, I compared weights of adult apterae from naturally occurring colonies with weights of caged individuals (Figs, 2 and 4). The latter were weighed within $24 \mathrm{~h}$ of first reproduction. Because ages of field collected adults varied and because weight generally increases after first reproduction (e.g. MacKay \& Downer, 1979), field weights are expected to be greater; however, this difference is slight compared to those occurring between hosts and seasons. If one also compensates for time since birth, weights from field collections show the same trends as those of caged aphids: weights on E.strigosus decline only slightly, while those on Solidago species drop more sharply. In field and cage data, weights decline sooner on S.nemoralis than on S.juncea, though by midJuly both are equally low in quality, as indicated by long developmental times and low adult weights (Figs. 1-3).

The trend in adult weight results partly from seasonal differences in temperature rather than from changes in host properties. 
However, host properties definitely influence adult size: aphids reared simultaneously on different hosts achieve different sizes (Table 1 ), and size declines much more on S.nemoralis and S.juncea than on E.strigosus. The autumn weight increase probably results from lower temperatures and not from improved host quality since it occurs on all hosts and since fecundities and developmental times do not similarly improve (Fig. 1, Table 1).

Soluble nitrogen. Soluble nitrogen content provides an independent index of seasonal changes in host properties. Admittedly, soluble nitrogen may not correspond with host quality, for several reasons (van Emden, 1969; van Emden \& Bashford, 1969, 1971). Host species may differ in aspects of quality not related to nitrogen, in proportion of soluble nitrogen actually present in phloem sap, or in amino acid balances. Despite these drawbacks, seasonal changes in soluble nitrogen should reflect relative changes in quality among host species.

Soluble nitrogen declines in all hosts between spring egg hatch and mid-summer (1 May to 1 August) (Fig. 5). Both the extent of decline and even absolute levels correspond to the relative suitabilities of the plant species.

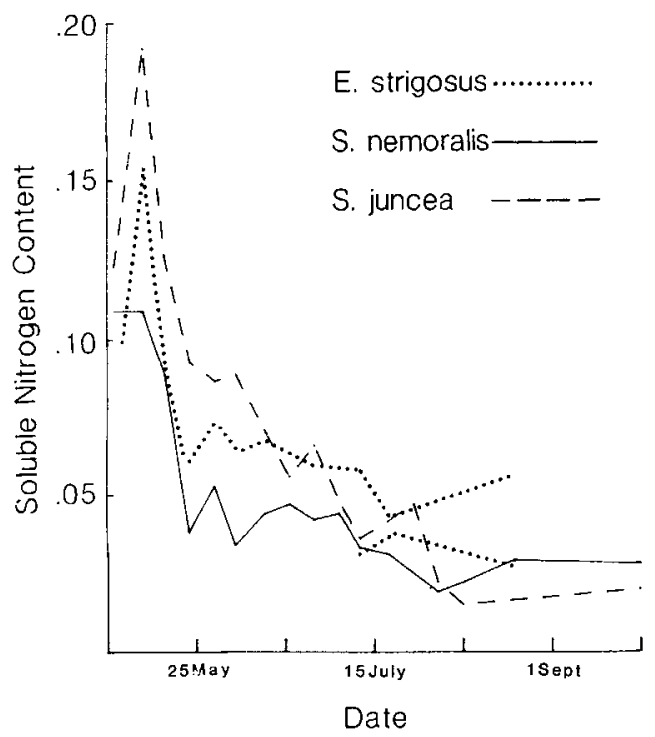

FIG. 5. Soluble nitrogen concentrations versus season in hosts of Uroleucon gravicome. After 20 June, values for Erigeron strigosus are divided into stems with all heads open (lower line) and stems with one or more head unopened (upper line).
In May the ranking of soluble nitrogen levels is S.juncea > E.strigosus $>$ S.nemoralis; in summer the ranking is E.strigosus $>$ S.nemoralis $>$ S.juncea. Between 1 May and 25 May, soluble nitrogen declines less rapidly in S.juncea than in S.nemoralis, remaining higher through most of June; similarly adult weight declines less rapidly on S.juncea. Overall decline in both aphid performance and soluble nitrogen is greater for S.juncea than for S.nemoralis. After mid-June, when E.strigosus begins to flower, I divided its stems into those with one or more heads not fully opened and those with all heads fully opened or beyond. Stems in earlier stages are preferred by alatae and have higher levels of soluble nitrogen (Fig. 5).

The correspondence between soluble nitrogen and reproductive performance supports the view that observed host shifts are an adaptation for optimal utilization of hosts with different seasonal patterns of favourability. Possibly, some covarying factor, and not nitrogen availability itself, is the important variable in host quality.

\section{Seasonal changes in host preferences and usage}

The earliest winged forms overwhelmingly prefer Erigeron to either Solidago species (Fig. 6). As the season progresses, both Solidago species are chosen with increasing frequency, though Estrigosus is always chosen more often than either Solidago species during spring (Fig. 6). Experiments were performed through mid-August, after which time few alatae are produced and few colonies initiated in the field.

Early in the season, field observations agree with results of preference tests. Except for rare fundatrix-initiated colonies, U.gravicorne does not occur on Erigeron until late May when alatae begin to mature on Solidago and begin to appear on Erigeron (Fig. 7).

Field data and choice experiments from late summer show somewhat conflicting patterns. In field censuses, the shift to Solidago begins later (early August) and is more sudden than is suggested by results of host choice experiments (Figs. 6 and 7). Possibly, experimental conditions altered criteria by which alatae normally choose hosts. Also, sudden increases in numbers of alatae seeking hosts 


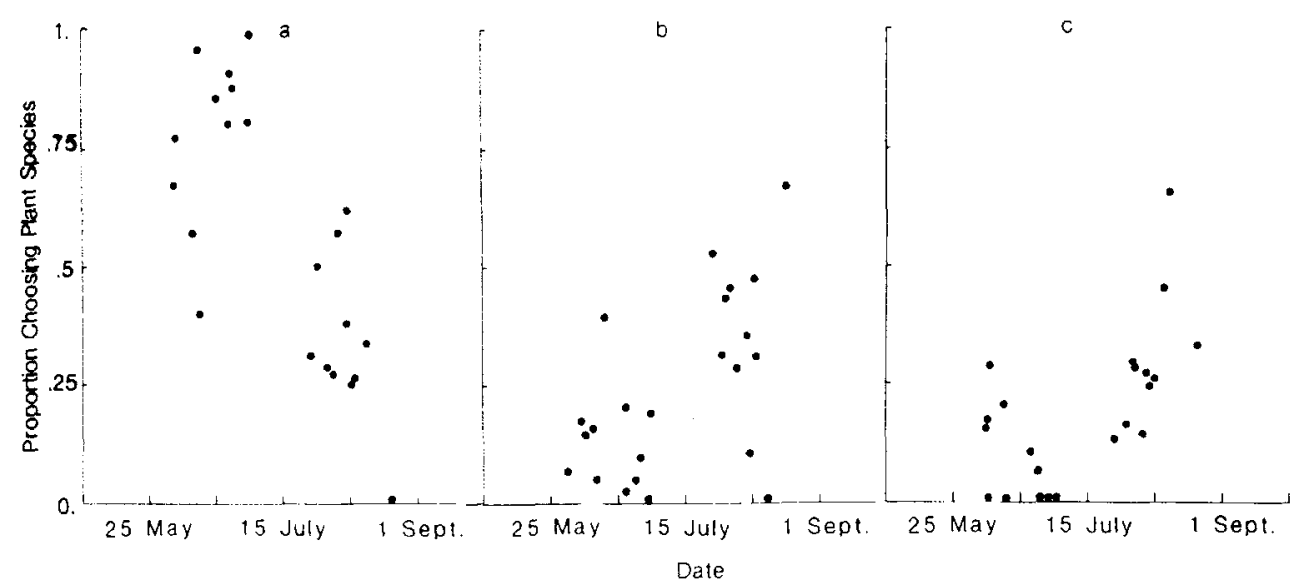

FIG. 6. Host preferences versus time of season for Uroleucon gravicorne. Points represent proportion of alatae in each choice experiment selecting (a) Erigeron strigosus, (b) Solidago nemoralis, and (c) Solidago juncea.

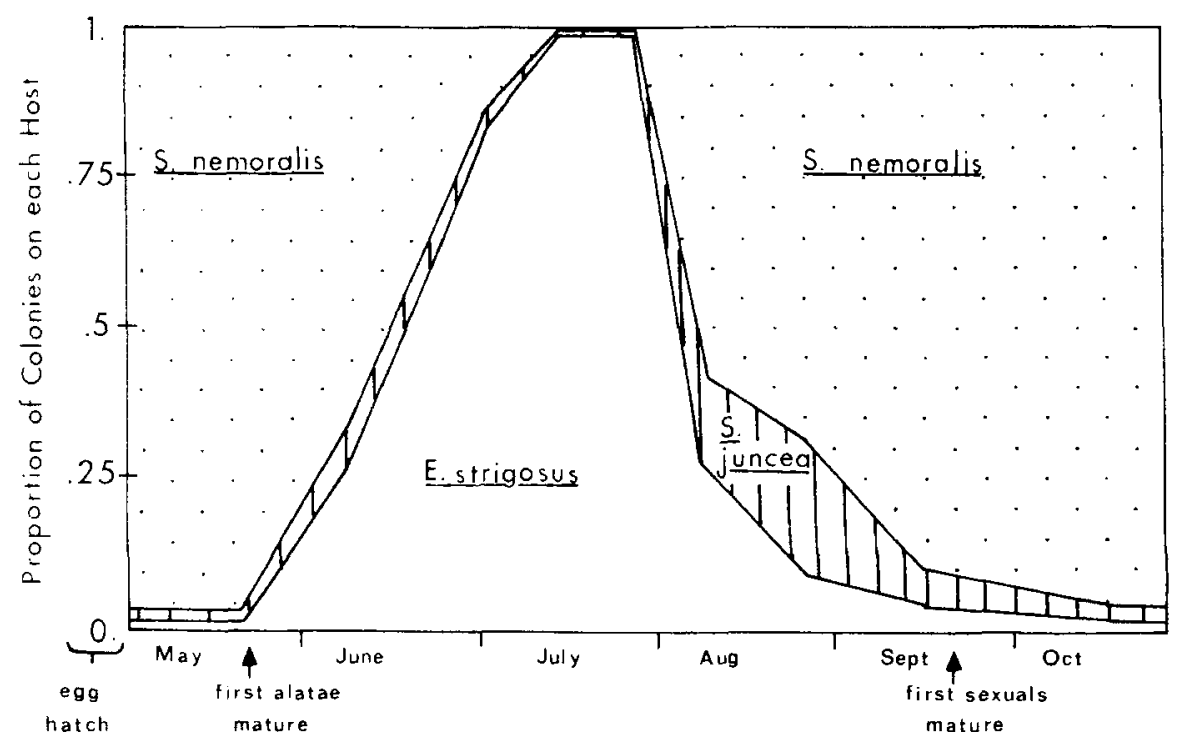

FIG. 7. Seasonal changes in proportions of Uroleucon gravicorne colonies on Erigeron strigosus, Solidago nemoralis, and Solidago juncea in three field sites in southern Michigan.

may give the appearance in the field of a discrete shift in preference towards Solidago even though preference for Solidago has been increasing over some time previously.

Host records from the literature and from museum collections show roughly similar trends, suggesting that U.gravicorne shifts host throughout its range (Fig. 8). The paucity of records from Solidago in spring probably results from Solidago being deserted before colonies are large and conspicuous to collectors. Recolonization of Solidago occurs in midAugust, as in ESGR field sites (Figs. 7 and 8 ). The main discrepancy results from seven collections on Erigeron in October: all were collected by Olive from E.canadensis in North Carolina, the southernmost area included in the records. 


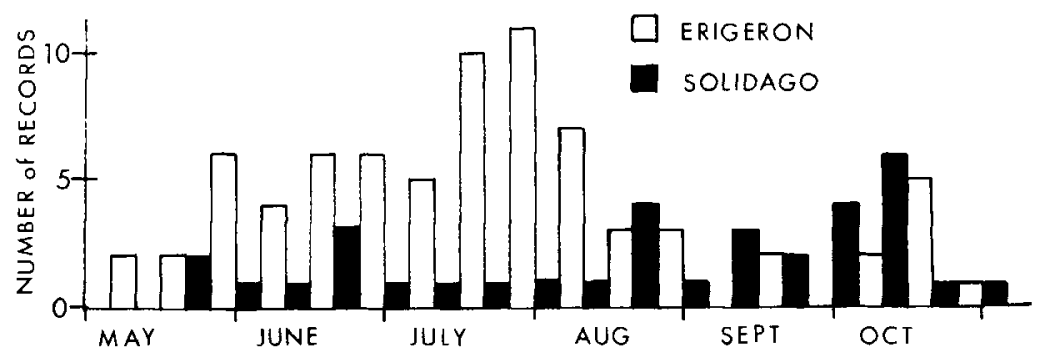

FIG. 8. Occurrence of Uroleucon gravicorne on Erigeron and Solidago according to season. Host records are taken from the literature and from muse um collections (see text).

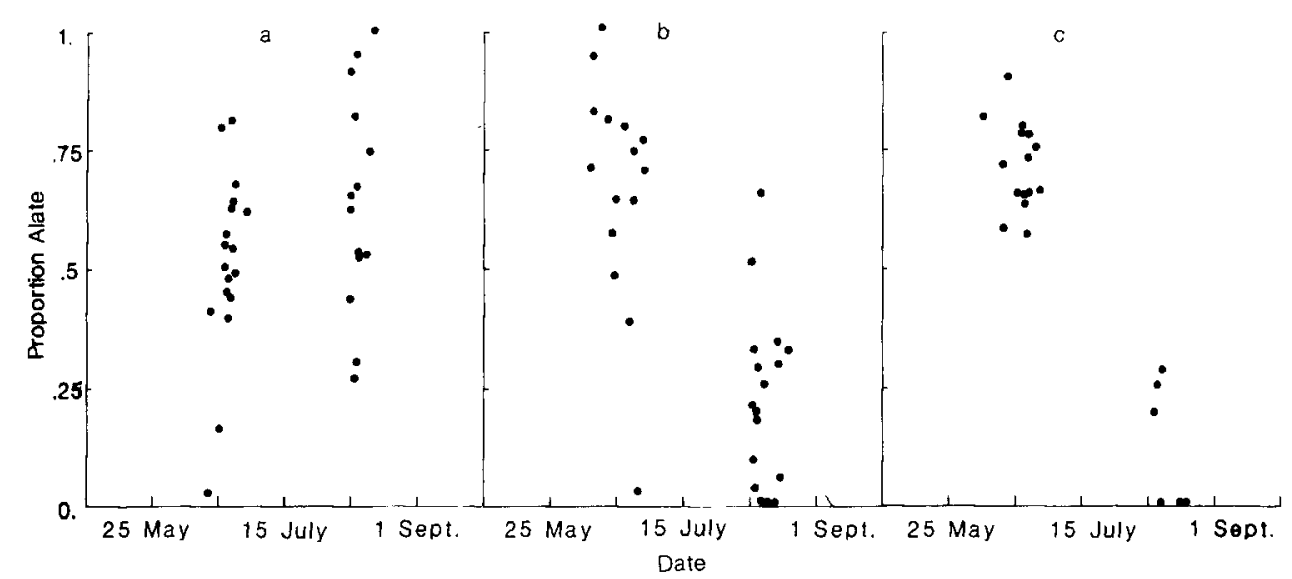

FIG. 9. Relative production of alate and apterous morphs versus time of season for Uroleucongravicorne caged on (a) Erigeron strigosus, (b) Solidago nemoralis, and (c) Solidago juncea.

\section{Morph production}

On both Solidago species, winged forms predominate in the progeny produced before 15 July; thereafter, their proportions decrease greatly, especially on S.juncea (S.nemoralis: $R^{2}=0.50$, slope $=0.0068, \quad P<0.0001$; S.juncea: $\quad R^{2}=0.69$, slope $=0.0064, \quad P<$ 0.0001 ; Fig. 9). On E.strigosus there is a slight and non-significant increase in proportion of winged progeny $\left(R^{2}=0.11\right.$, slope $=0.0032$, $P=0.06$ ), with high variability among broods.

\section{Discussion}

As in typical host-alternating aphids, shifts in host preference in U.gravicorne appear to be 'programmed' and not simply the result of colonizing the best host available at the moment and remaining until it becomes crowded or less nutritious. In fact, trends in host choice are approximately inversely related to trends in host quality. Thus, preference for and field colonization of Solidago increases during mid- to late summer when E.strigosus is superior (Fig. 6, Table 1). Actually, my measures of reproductive performance suggest that Erigeron is always superior to S.nemoralis, leaving unexplained colonization of Solidago in autumn and spring Furthermore, both fundatrices and oviparae can and sometimes do live on Erigeron (Fig. 7, Table 1). In nature, host species may have differential effects not evident in the type of data I have presented; all stages in the herbivore's life cycle must be considered in order to understand relationships with host species.

One reason for use of Solidago may be that by 1 August many E.strigosus are beginning to senesce and will die before either new alatae or oviparae can be produced. More importantly, perennial hosts such as Solidago species may provide superior oviposition sites. First 
instar fundatrices hatching from eggs laid on or near bases of Solidago stems will usually be near food, depending on the pattern of rhizome production; eggs on annuals will be near spring food supply only if other foodplants are growing nearby. Thus, avoidance of Erigeron in autumn may be part of a generalized ability to recognize and avoid senescent plants which will not live long enough to support development of sexuals, or it may be a more specific adaptation for putting autumn colonies (and thus oviparae and eggs) on host taxa more favourable for hatching fundatrices.

Similarly, in other heteroecious aphids, return to the winter host may benefit not the morphs actually possessing adaptations for locating and feeding on these plants in autumn, but rather the first few descendant spring generations. Certainly in Eriosomatinae, any advantage of complementary host growth patterns is enjoyed by spring generations; the winter host is not used at all for food in autumn, by either sexuparae (which fly to the winter host) or their non-feeding sexual offspring. In the aphidine Rhopalosiphum padi $\mathrm{L}$. as well, gynoparae and oviparae, the morphs which feed on bird cherry (Prunus padus L.) in autumn, show very low reproductive rates, averaging fewer than two nymphs per gynopara and less than one egg per ovipara (Leather, 1980). The many gynoparae which fail to locate hosts further increase the cost of moving in autumn. However, oviposition on bird cherry provides fundatrices with easily located, high quality food, enabling very high reproductive rates in spring (Leather \& Dixon, 1981). Examples from other herbivorous insect groups suggest that oviposition preferences, adaptations for placing progeny in favourable circumstances, may often outweigh benefits of immediate optimization of diet (Claridge \& Wilson, 1978; Claridge et al., 1977).

Why is S.juncea utilized less than S.nemoralis during spring, despite its apparent nutritional superiority? Both are perennials and begin to grow at the same time in spring; in this regard they are similar from the point of view of hatching fundatrices. The earlier flowering and senescence of S.juncea may prevent its utilization in spring; as in E.strigosus, most stems are dead before maturation of oviparae. Late summer alatae do colonize both Solidago species (Figs. 6 and 7). On S.nemoralis, these colonies always produce sexuals and overwintering eggs, whereas S.juncea stems drying out before mid-September are deserted without production of sexuals - through the production of alatae.

Feeding is possible though rare on Solidago in mid-summer. R.padi cannot reproduce on its winter host in mid-summer (Dixon, 1971), while Aphis fabae Scop. can and does if natural enemies are removed, permitting persistence of spring colonies (Way \& Banks, 1968). Natural enemies are not common in spring on Solidago but may still be responsible for eliminating persistent U.gravicorne colonies.

In most host-alternating aphids, the summer host is more recently acquired (Eastop, 1977). U.gravicorne probably fed originally only on Solidago, since its closest relatives [U.cadens Moran, U.caligatum (Richards) and U.tissoti (Boudreaux)] are restricted to Solidago. Other Lambersius species do feed on Erigeron, e.g. U.erigeronensis (Thomas) and U.macgillivrayae (Olive) but are less closely related to U.gravicorne (Moran, 1982).

Similarity between seasonal host shifts in U.gravicorne and in other aphids is clearly due to convergence, and host alternation has evolved multiple times in aphids (Eastop, 1972, 1977; Hille Ris Lambers, 1950, 1979). The phenomenon is rare in other herbivorous insects suggesting that some features of aphids cause host alternation to evolve frequently.

Among properties predisposing aphids to host alternation is the large number of generations per year, made possible by parthenogenesis and telescoping of generations. This promotes movement between individual plants in two ways. First, colonies fill plants quickly and thus must disperse to new plants for continued expansion. Second, lineages (in this case clones) go through many adult, and thus potentially winged (dispersive), stages. If aphids are already forced to move between host individuals, then shifts between host taxa are less costly and can evolve more easily.

Also important, though not unique to aphids, is the predictability of fluctuations in host quality. Most of aphid evolution has taken place in temperate areas where primary determinants of food plant quality are the 
regular cycles in phloem nutrient content arising from yearly growth cycles.

These two hypothesized predisposing characteristics are attractive in that they apply to aphids but not to most herbivorous insects. However, they fail to explain host alternation in the aphidoid family Adelgidae which is oviparous, thus lacking telescoping of generations and which alternates between conifers in 2 year rather than 1 year cycles. Possibly, the extension to 2 years (also found in Hormaphidinae and Fordinae, see Eastop, 1977) evolved secondarily. Still, by themselves, the factors suggested also fail to explain other recurring features of heteroecious life cycles, particularly why summer generations are less host specific and why summer hosts are almost always more recently acquired. In other words, why have monophagous aphids on herbaceous taxa not sometimes acquired perennials as winter hosts? The most promising hypothesis is that the high level of specialization of fundatrices has caused selection to favour lineages which utilize newly abundant, favourable plants in summer but which return to the ancestral host for production of sexual females (Mordvilko, 1928; Kennedy \& Stroyan, 1959).

In U.gravicorne, however, all morphs including fundatrices could reproduce as well or better on Erigeron. Thus, neither of the two major hypotheses for host alternation is applicable; host shifts can be attributed neither to overspecialization of certain morphs (so that the ancestral host is retained despite superiority of the newer host) nor to simple maximization of nutrient intake (so that both hosts are retained because each is nutritionally superior at some time of the season). I have argued that fundatrices hatching on S.nemoralis are more likely to locate food; this benefit to retaining the winter host may be widespread in heteroecious aphids, given the typical growth forms of winter and summer hosts. These results for U.gravicorne add to accumulating evidence that patterns of host usage by herbivorous insects can be understood only by considering ecological factors other than nutritional quality.

\section{Acknowledgments}

R. D. Alexander, T. J. Cohn, R. Hagen, W. D. Hamilton, L. R. Kirkendall, T. E. Moore and
A. G. Robinson gave useful comments on a preliminary draft of the manuscript. Financial support was provided by the National Science Foundation, the University of Michigan Museum of Zoology, and the Rackham School of Graduate Studies. This paper is from a Ph.D. dissertation submitted to the University of Michigan.

\section{References}

Claridge, M.F., Reynolds, W.J. \& Wilson, M.R. (1977) Oviposition behaviour and food plant discrimination in leafhoppers of the genus Oncopsis. Ecological Entomology, 2, 19-25.

Claridge, M.F. \& Wilson, M.R. (1978) Oviposition behavior as an ecological factor in woodland canopy leafhoppers. Entomologia Experimentalis et Applicata, 24, 101-109.

Derman, B.D., Rupp, D.C. \& Nooden, L.D. (1978) Mineral distribution in relation to fruit development and monocarpic senescence in Anoka soy beans. American Journal of Botany, 65, 205213.

Dixon, A.F.G. (1971) The life-cycle and host preferences of the bird cherry-oat aphid, Rhopalosiphum padi L., and their bearing on the theory of host-alternation in aphids. Annals of Applied Biology, 68, 135-147.

Eastop, V.F. (1972) Deductions from the present day hosts of aphids and related insects. Insect/ Plant Relationships (ed. by H. F. van Emden), pp. 157-178. Blackwell Scientific Publications, Oxford.

Eastop, V.F. (1977) Worldwide importance of aphids as virus vectors. Aphids as Virus Vectors (ed. by K. F. Harris and K. Maramorosch), pp. 3-47. Academic Press, London.

Hille Ris Lambers, D. (1950) Hostplants and aphid classification. Proceedings of the International Congress of Entomology, 8, 141-144.

Hille Ris Lambers, D. (1966) Polymorphism in Aphididae. Annual Review of Entomology, 11, 47-78.

Hille Ris Lambers, D. (1979) Aphids as botanists? Symbolae Botanicae Upsalienses, 22, 114-119.

Hottes, F.C. \& Frison, T.H. (1931) The plant lice, or Aphidae, of Illinois. Illinois Natural History Survey Bulletin, 19, 121-447.

Kennedy, J.S. \& Stroyan, H.L.G. (1959) Biology of aphids. Annual Review of Entomology, 4, 139160.

Leather, S.R. (1980) Egg survival in the bird cherryoat aphid, Rhopalosiphum padi. Entomologia Experimentalis et A pplicata, 27, 96-97.

Leather, S.R. \& Dixon, A.F.G. (1981) Growth, survival, and reproduction of the bird cherry-oat aphid, $R$ hopalosiphum padi, on its primary host. Annals of Applied Biology, 99, $115-118$.

Leonard, M.D. (1936) Additions to the New York State list of aphids with notes on other New 
York species. Journal of the New York Entomo. logical Society, 44, 177-185.

Leonard, M.D. (1963) A list of the aphids of New York. Proceedings of the Rochester Academy of Science, 10, 289-428.

Leonard, M.D. (1964) Additional records of new Jersey aphids. Journal of the New York Entomo. logical Society, 72,79-101.

Leonard, M.D. (1967) Further records of New Jersey aphids (Homoptera: A phididae). Journal of the New York Entomological Society, 75,77-92.

Leonard, M.D. (1968) A supplement to a list of the aphids of New York. Proceedings of the Rochester Academy of Science, 11, 267-361.

Leonard, M.D. \& Bissell, T.L. (1970) A list of the aphids of District of Columbia, Maryland and Virginia. University of Maryland Agricultural Experiment Station, MP770, 1-129.

Mackay, P.A. \& Downer, R.G.H. (1979) Water content, weight change, and activity of apterous and alate virginioparous Acyrthosiphon pisum (Harris) (Homoptera: Aphididae). Canadian Journal of Zoology, 57, 363-367.

Melber, A., Klindworth, H.-G. \& Schmidt, G.H. (1981) Saisonaler Wirtspflanzenwechsel bei der baumbewohnenden Wanze Elasmucha grisea L. (Heteroptera: Acanthosomatidae). Zeitschrift für Angewand te Entomologie, 91, 55-62.

Mittler, M.E. (1953) A mino acids in phloem sap and their excretion by aphids. Nature, 172, 207.

Moran, N.A. (1982) Host relationships, life cycles, and systematics of aphids of the genus Uroleucon Mordvilko. Ph.D. dissertation, Division of Biological Sciences, University of Michigan, Ann Arbor, Michigan.

Mord vilko, A.K. (1928) The evolution of cycles and the origin of heteroecy (migration) in plant-lice.
Annals and Magazine of Natural History, 2,570582.

Olive, A.T. (1963) The genus Dactynotus Rafinesque in North Carolina (Homoptera: Aphididae). Miscellaneous Publications of the Entomological Society of America, 56, 556-559.

Parry, W.H. (1979) Summer survival of the green spruce aphid, Elatobium abietum, in North East Scotland. Oecologia (Berlin), 41, 235-244.

Patch, E.M. (1919) Three pink and green aphids of the rose. Maine Agricultural Experiment Station Bulletin, 282, 205-218.

Richards, W.R. (1972) Review of the Solidagoinhabiting aphids in Canada with descriptions of three new species (Homoptera: Aphididae). Canadian Entomologist, 104, 1-34.

van Emden, H.F. (1969) The differing reactions of Brevicoryne and Myzus to leaf age, turgidity and soluble nitrogen in brassicas. Annals of Applied Biology, 63, 324-326.

van Emden, H.F. \& Bashford, M.A. (1969) A comparison of the reproduction of Brevicoryne brassicae and Myzus persicae in relation to soluble nitrogen concentration and leaf age (leaf position) in the Brussels sprouts plant. Entomologia Experimentalis et Applicata, 12, 351-364.

van Emden, H.F. \& Bashford, M.A. (1971) The performance of Brevicoryne brassicae and Myzus persicae in relation to plant age and leaf amino acids. Entomologia Experimentalis et Applicata, $14,349-360$.

Way, M.J. \& Banks, C.J. (1968) Population studies on the active stages of the black bean aphid, Aphis fabae Scop., on its winter host, Euonymus europaeus L. Annals of Applied Biology, 59, $175-188$.

Accepted 24 February 1983 